\title{
Faultless Disagreement Contextualism
}

\begin{abstract}
Alex Davies*
Received: 1 December 2020 / Revised March 292021 / Accepted: 11 May 2021

Abstract: It is widely assumed that the possibility of faultless disagreement is to be explained by the peculiar semantics and/or pragmatics of special kinds of linguistic construction. For instance, if A asserts "o is F" and B asserts this sentence's denial, A and B can disagree faultlessly only if they employ the right kind of predicate as their " $F$ ". In this paper, I present an argument against this assumption. Focusing on the special case when the expression of interest is a predicate, I present a series of examples in which the same pairs of sentences are employed, but in different contexts. In some cases, we get an impression of faultless disagreement and in some cases we don't. I identify a pattern across these contexts and conclude that faultless disagreement is made possible, not by a special kind of predicate, but instead by a special kind of context.
\end{abstract}

Keywords: Disagreement; faultless disagreement; instrumental reasons; objectivity.

\section{The subjective predicate}

When is it possible for a state of disagreement to be faultless; for there to be a bona fide state of disagreement but neither party has made

* University of Tartu

(iD) https://orcid.org/0000-0001-9978-0665

University of Tartu, Ülikooli 18, 50090 Tartu, Estonia.

$\triangle$ alexander.stewart.davies@ut.ee

(C) The Author. Journal compilation (c) The Editorial Board, Organon F.

This article is distributed under the terms of the Creative Commons Attribution-NonCommercial 4.0 International Public License (CC BY-NC 4.0). 
a mistake? Here is one widely (but not universally) assumed and tempting answer. Suppose A asserts a sentence of the form "o is F" and B asserts the (internal) negation of this sentence. It is thought that whether A and $\mathrm{B}$ could be in a faultless state of disagreement is decided by the kinds of predicate employed in the asserted sentences - it is the predicates employed which decide whether faultless disagreement is possible. Let's call the predicates that many believe to be the enablers of the possibility of faultless disagreement "subjective predicates." Different authors may believe that different sets of predicates are subjective (compare for instance Stojanovic (2019) with those she disagrees with). But typically these predicates include predicates of personal taste, aesthetic predicates and other evaluative predicates. Whichever predicates these are precisely, they are a proper subset of predicates, and the authors believe the following about them:

(SP) It is possible for A and B to be in a state of disagreement without either being at fault only if their assertions include use of a subjective predicate.

Philosophers and linguists (e.g. Huvenes 2014, 144-45; Kennedy 2013, 259; Kölbel 2003, 21-22; Lasersohn 2005, 644; MacFarlane 2014, 2-3; Palmira 2015, 15; Solt 2018, 64; Umbach forthcoming, 2; and Wright 2001, 46-47) betray commitment to (SP) when they sort apparent disagreements into those that can be faultless, and those that cannot, more or less purely on the basis of the predicates used to express the disagreement. For instance, we might be presented with two apparent disagreements:

Office Quality

Kris: $\quad$ The Office is funny.

Badr: $\quad$ The Office isn't funny.

Office Author

Colleague: Ricky Gervais is the author of The Office.

Thomas: Ricky Gervais is not the author of The Office.

Without reference being made to anything beyond the pair of assertions, it is then claimed that in Office Author either at least one of the parties is at fault or they aren't really in a state of disagreement, yet, in contrast, this 
is not so in Office Quality - as if we don't need to know anything else in order to ascertain whether either apparent disagreement can be faultless. In presenting faultless disagreements in this way, theorists of the phenomenon betray commitment to (SP). For if one cannot tell just by looking at the predicates employed whether an apparent disagreement is faultless, then one cannot distinguish Office Quality from Office Author in this way. Yet theorists think they can.

I will argue against (SP). ${ }^{1} \mathrm{I}$ don't think the possibility of faultless disagreement for exchanges of the kind between $\mathrm{A}$ and $\mathrm{B}$ has its origin in the predicates employed. I think it is a phenomenon that arises when the reasons for which A and B make their assessments of whether o is $\mathrm{F}$ are, in a sense to be clarified, permissive with respect to the criteria that fix what counts as F.

Sections 2-5 present the case against (SP). Section 6 describes some implications of the argument against (SP) for both a relativist analysis of subjective predicates and for a constructivist account of faultless disagreement that several contextualists seem to favour. Section 7 defends the argument presented in sections 2-5 against four objections.

I do not aim to convince just anybody that faultless disagreement, where it does arise, does not arise because of the peculiar properties of a special kind of predicate. There are those who deny that faultless disagreement is ever possible with any predicate (e.g. Glanzberg 2007, 16; Stojanovic 2007, 693-96). I aim to convince only those who already accept that faultless disagreement is possible at all that there is good reason to believe that it can in principle arise for any context-sensitive predicate.

I also do not mean to deny, in what follows, that there are differences between predicates which can be described with the words "subjective" and "objective." I particularly have in mind the capacity of some adjectives (possibly different ones in each case) but not others: to appear in the complement position of "find"; to felicitously combine with an explicit experiencer argument; and to require that the speaker have the right kind of first-

1 Zakkou $(2019,17)$ explicitly acknowledges that judgements about whether a given pair of assertions constitutes a case of faultless disagreement are context-sensitive. But this observation is made in defence of the possibility of faultless disagreement altogether rather than as an observation which might threaten (SP).

Organon F 28 (3) 2021: 557-580 
hand experience. I am not going to try and convince anyone that if you put a predicate in the right context, all this can be had. I am concerned only to deny that a special kind of predicate is a necessary enabling condition of, specifically, faultless disagreement.

\section{Reasons for making an assessment: the same, different and the same again}

I want to draw your attention to an interplay between the reasons for which $\mathrm{A}$ and $\mathrm{B}$ engage in an assessment of whether something is $\mathrm{F}$ and our intuitive judgements about whether $\mathrm{A}$ and $\mathrm{B}$ disagree with each other, and if they do, whether their disagreement is one in which somebody has to be mistaken. We'll begin with, and will subsequently riff upon, an example from Richard (2004):

Didi (in her context C1): Mary's rich.

Naomi (in her context C2): Mary is not rich at all.

Richard defines $\mathrm{C} 1$ and $\mathrm{C} 2$ as follows:

Example 1

Suppose, to take an example, that Mary wins a million dollar lottery. Didi is impressed, and remarks to a friend 'Mary's rich.' Naomi, for whom a million dollars is not really all that much, remarks in a conversation disjoint from Didi's, 'Mary is not rich at all'... Suppose that there is no difference between the two conversations in the point of assessing people as rich or otherwise. (Each conversation began with the observation that some wealthy person doesn't deserve to be rich, and each of the women is now idly assessing people as rich or otherwise, and then assessing whether the rich ones deserve their wealth.) (Richard 2004, 218)

Looking at this, it seems that Didi and Naomi disagree: Didi thinks that Mary is rich whereas Naomi thinks that Mary is not rich. Moreover, it doesn't seem that one of them must be mistaken in making the assertion that she does. In other words, there's not much to distinguish this pair of assertions from Office Quality. It seems to be a case of faultless disagreement. 
Let's now consider two variations on example 1.

Example 2

Suppose that Mary wins a million-dollar lottery. Didi is talking with a good friend, of modest income, who's just suffered a burglary: all the children's Christmas presents were stolen, and they don't have the money to buy any replacements. Didi, hearing this sob story, remembers Mary. "Hey, Mary's got a good heart. And she's just won the lotteryliterally. Mary's rich. I'm sure she'd help you guys out." Naomi, herself someone for whom a million dollars is not a lot of money, has a friend who is looking for someone who might buy his apartment: worth 98 million dollars. Her friend remembers that Mary was looking to buy a new apartment and asks Naomi to inquire into whether Mary would be interested. But Naomi replies, "Mary? Mary's not rich. You're barking up the wrong tree with her."

Here, we once again get faultlessness: it doesn't seem that either of Didi or Naomi is making a mistake in her assertion - they're both right. However, in marked contrast to Richard's original example 1, it's pretty clear that here Didi and Naomi are not in a state of disagreement with each other.

Finally, consider this:

\section{Example 3}

Suppose that Mary wins a million-dollar lottery. Didi is talking with a good friend, of modest income, who's just suffered a burglary: all the children's Christmas presents were stolen, and they don't have the money to buy any replacements. Didi, hearing this sob story, remembers Mary. "Hey, Mary's got a good heart. And she's just won the lotteryliterally. Mary's rich. I'm sure she'd help you guys out." In a different conversation in another part of the city, Naomi hears the same sob story and is asked whether she knows anyone who might be kind-hearted and wealthy enough to help out the family. She's asked specifically about Mary in this regard. Naomi replies, "Mary? Mary's not rich. You're barking up the wrong tree with her."

Here, we get the reverse of what we had in example 2. We get disagreement - just as we had in example 1-but we've lost faultlessness: Naomi is mistaken - she's saying something false. 
In all three examples we have two assertions, each assertion taking place in a different conversation from the other in the pair. But in example 1, we seem to get both a state of disagreement and the sense that neither party to the disagreement is mistaken. In example 2, we retain faultlessness but we lose disagreement. And in example 3, we retain disagreement but we lose faultlessness. So what's making the difference?

\section{Permissive reasons for making an assessment}

Instrumental reasons are the kind of reason you give for doing something when you say it is a means to some further end (Kolodny 2018). For instance, my reason for walking into town is to buy milk. My reason for driving right now is that I'm going to Watford. Notice that if you're doing one thing for the reason that you're doing something else, then that something else often introduces constraints on how you should do that thing. If you're driving to Watford, then when you approach a particular T-junction, it may well be the case that you ought to turn a certain direction, because that's the way to Watford and the other direction is not. Thus, the reason for which you're driving introduces normative constraints upon how you drive. The same is true of an assessment of whether o is $\mathrm{F}$ and the reasons for which you are making the assessment. Sometimes the reason for which you're making an assessment of whether o is F introduces normative constraints on the criteria you ought to employ for what counts as F, just as the reason for which you're driving introduces normative constraints on how you drive.

With this in mind, think back to the examples just provided. For what reasons are Didi and Naomi making assessments of whether Mary is rich? Answer: for different reasons in the different examples. In example 1, they are both making their assessments "idly" as the basis for subsequent discussion about whether rich people deserve their money. If the assessments are idle, this presumably means there's nothing about the reasons for which they make their assessments which could be appealed to in defending either the inclusion of Mary in, or the exclusion of Mary from, the set of rich people. In example 2, things are different. Here neither Didi nor Naomi is idly making her assessment: the reason why Didi is making the assessment 
is in search of someone who could help out her friend and her friend's family for Christmas. The reason why Naomi is making the assessment is in search of someone who has wealth enough to purchase a 98 million-dollar apartment. Intriguingly, in this example, their reasons do provide something which could be appealed to in defending either the inclusion of Mary in, or the exclusion of Mary from, the set of rich people. With respect to Didi's reason for making her assessment: all that matters for achieving Didi's overarching goal is that someone be identified who has ample disposable savings to spare some money to buy some Christmas presents for a family of modest income. Given that in making her assessment, this was all Didi was doing, and given that Mary has suddenly got an excess of one million dollars, Mary fits that bill. For this purpose, Mary should be classified as rich. With respect to Naomi's reason for making her assessment: all that matters for Naomi's overarching goal is that someone have enough disposable income to afford a 98 million-dollar apartment. Mary does not fit this bill. For this purpose, Mary should not be classified as rich. So in example 2, we have divergent purposes and each purpose places normative constraints on whether Mary should be considered rich (for the respective purpose), which were absent in example 1. In example 3, with respect to the reasons why Didi and Naomi are making their respective assessments, things are different once again. This time, just like in example 1, each of Didi and Naomi is making her assessment for the same reason but the reason isn't the same as in example 1. This time it's the reason Didi was making her assessment in example 2: i.e. in search of someone who could help out the unfortunate friend and her family for Christmas. Just as in example 2, if the assessment is being made for this reason, then Mary ought to be counted as rich. This has the result that when Naomi denies that Mary is rich, she seems to be incorrect, given the reason for which she's making the assessment of whether Mary is rich.

There are two variables I think it's worth keeping track of across these examples: whether there is a divergence of reasons for assessment between Didi and Naomi; and whether the reason for the assessment is the kind of thing that can be appealed to in defence of a particular criterion for being rich. Let's give a name to this kind of reason. A "permissive reason" is a reason for which you perform an assessment of whether o is $\mathrm{F}$ that satisfies the following condition: 
Permissive reason

A reason $\mathrm{r}$ for making an assessment of whether $\mathrm{o}$ is $\mathrm{F}$ is permissive with respect to two criteria for deciding whether o is $\mathrm{F}$ if $\mathrm{r}$ permits those two criteria and according to one, o won't count as F, but according to the other, o will count as F.

Reason $r$ permits a criterion if it doesn't require (in the way that instrumental reasons can require things of that for which they are a reason) that one use another criterion.

In the examples provided, the interaction between these two variables and the felt presence of faultless disagreement can be described with the following table:

\begin{tabular}{c|ccc}
\hline & $\begin{array}{c}\text { Both } \\
\text { permissive }\end{array}$ & $\begin{array}{c}\text { Both } \\
\text { not-permissive }\end{array}$ & $\begin{array}{c}\text { One permissive, } \\
\text { one not-permissive }\end{array}$ \\
\hline \multirow{2}{*}{$\begin{array}{c}\text { Same } \\
\text { reason }\end{array}$} & $\begin{array}{c}\text { Faultlessness } \\
\text { Disagreement } \\
(\text { Example 1) }\end{array}$ & $\begin{array}{c}\text { No faultlessness } \\
\text { Disagreement } \\
(\text { Example 3) }\end{array}$ & NA \\
\hline Different & & Faultlessness \\
reason & $?$ & $\begin{array}{c}\text { No disagreement } \\
(\text { Example 2) }\end{array}$ & $?$ \\
\hline
\end{tabular}

Table 1

Let's now try to fill in the two question-marks. We can do that by considering two more examples, once again, riffing on Richard's original.

\section{Example 4}

Didi's in a conversation that began with the observation that some wealthy person doesn't deserve to be rich, and Didi and her friend are now idly assessing people as rich or otherwise, and then assessing whether the rich ones deserve their wealth. Suppose that Mary wins a million-dollar lottery. Didi is impressed, and, in the course of this conversation, she remarks to her friend 'Mary's rich.' In another part of town, a friend of Naomi's has expressed an interest in meeting someone rich, just to know what it feels like. The friend suggests Mary as an 
option - with her newfound wealth. Naomi, for whom a million dollars isn't a lot of money, rejects the idea, "Oh no. Mary's not rich."

Do Didi and Naomi disagree? I think they do: were they to meet, you couldn't appeal to their differing reasons for making their assessments to demonstrate that they don't really disagree. And I also think there's nothing wrong with either assertion. In this example, we have two different reasons why assessments are being made of whether Mary is rich. Yet in contrast with example 2, both of these reasons could reasonably be described as "permissive": neither provides us with a basis upon which we could defend a particular stance on how to classify Mary vis a vis being rich: the reasons don't favour one criterion over another.

Look now at a final variation on Richard's example 1:

\section{Example 5}

Didi's in a conversation that began with the observation that some wealthy person doesn't deserve to be rich, and Didi and her friend are now idly assessing people as rich or otherwise, and then assessing whether the rich ones deserve their wealth. Suppose that Mary wins a million-dollar lottery. Didi is impressed, and, in the course of this conversation, remarks to her friend 'Mary's rich.' In another part of town, Naomi, herself someone for whom a million dollars is not a lot of money, has a friend who is looking for someone who might buy his apartment: worth 98 million dollars. Her friend remembers that Mary was looking to buy a new apartment and asks Naomi to inquire into whether Mary would be interested. But Naomi replies, "Mary? Mary's not rich. You're barking up the wrong tree with her."

My impression here is that although each of Didi and Naomi is making no mistake in making the assertion that she does, they are not in a state of disagreement with each other. In this example, we have a divergence of reasons for which assessments are being made, and one of these reasons is permissive (Didi's) whereas the other reason (Naomi's) is not.

These two examples allow us to complete the table: 


\begin{tabular}{c|ccc}
\hline & Both permissive & $\begin{array}{c}\text { Both not-permis- } \\
\text { sive }\end{array}$ & $\begin{array}{c}\text { One permissive, } \\
\text { one not-permissive }\end{array}$ \\
\hline $\begin{array}{c}\text { Same } \\
\text { reason }\end{array}$ & $\begin{array}{c}\text { Faultlessness } \\
\text { Disagreement } \\
\text { (Example 1) }\end{array}$ & $\begin{array}{c}\text { No faultlessness } \\
\text { Disagreement } \\
\text { (Example 3) }\end{array}$ & NA \\
\hline $\begin{array}{c}\text { Different } \\
\text { reason }\end{array}$ & $\begin{array}{c}\text { Faultlessness } \\
\text { Disagreement } \\
(\text { Example 4) }\end{array}$ & $\begin{array}{c}\text { Faultlessness } \\
\text { No disagreement } \\
\text { (Example 2) }\end{array}$ & $\begin{array}{c}\text { No disagreement. } \\
\text { (Example 5) }\end{array}$ \\
\hline
\end{tabular}

Table 2

At this point, it becomes tempting to formulate a hypothesis on the basis of the pattern witnessed in the table. At the start of this paper, we considered the generic situation in which A asserts a sentence of the form "O is F" and $\mathrm{B}$ its negation. A and B are each making an assessment of whether o is $\mathrm{F}$ but coming down on different sides of the issue. The pattern seen in the table suggests that A and B can be in a state of faultless disagreement only if the reasons for which they make their respective assessments are both permissive with respect to how to assess whether o is $\mathrm{F}$-where this does not mean they have to be making their assessments for the same reason (see example 4).

\section{Predicates of personal taste and non-permissive reasons for making an assessment}

If this hypothesis is correct, then we should expect it to apply to assertions made using paradigmatically subjective predicates as well. In particular, we should expect to be able to block an impression of faultless disagreement by appropriate modification of the reasons for which asserters are making their respective assessments of whether some o is F. Let's see if we can do that:

\section{Example 6}

Maksim's job is to visit stand-up comedians doing a gig and find out whether their kind of humour would suit the audience of the Comedy 
Cellar, where his boss works. To do this, Maksim broadcasts the gig to a sample of the Comedy Cellar audience. Members of the sample can then give an indication of whether they think the comedian is funny. Maksim watches a comedian who calls herself Sergeant Knock Knock. The sample listens. The sample is unimpressed. Maksim's boss calls Maksim to ask for the verdict. "So, is she funny?" "No, she's not funny. We better go with that other one from last week." Nikolai is at the same gig doing the same thing - but Nikolai works for the Comedy Penthouse, a different club. It's well known that their clientele have a different sense of humour to those folks down at the Comedy Cellar. Nikolai's boss calls him up, and asks for the verdict, "So, is she funny?" "Yes, she is funny. We should get her up to the Comedy Penthouse next week if we can."

It seems to me that neither Maksim nor Nikolai are at fault in making their respective assertions. However, they aren't in a state of disagreement with each other. This is as we would expect because example 6 is modelled on example 2. But things change if we approximate the kind of situation we see in example 1:

\section{Example 7}

Nikolai heads on over to his local, and Maksim over to his, where each meets with his respective gang of friends. Nikolai's friends ask (just to break the ice as Nikolai arrives) how the act was. Thinking how he personally felt about Sergeant Knock Knock, Nikolai replies, "She wasn't funny. But the Comedy Penthouse audience liked her. So we'll be seeing more of her." Maksim's friends ask him the same question, and for the same idle, ice-breaking reason. Maksim replies, "She was funny. It's s a shame the Comedy Cellar's audience didn't agree."

Here it seems that Nikolai and Maksim do disagree and that neither of them need be mistaken in his assertion: as we would expect, given the parallel with example 1.

We could construct further parallels with examples 3-5. For instance, we could adapt example 6 so that it parallels example 3 by stipulating that Maksim and Nikolai work for the same comedy club. But for reasons of space, I won't do this. It should nonetheless be clear that an impression of faultless disagreement comes and goes with changes of context just as 
much for assertions that deploy a paradigmatically subjective predicate ("is funny") as for assertions that deploy another kind of predicate ("is rich").

\section{Rejecting (SP)}

I conclude on the basis of these examples that (SP) is false. Whilst holding fixed the expressions employed in a pair of assertions, and whilst changing the contexts in which the assertions are made, we witness shifts in impressions of faultless disagreement. What seems to be important to the presence of an impression of faultless disagreement is that the assessments of whether $\mathrm{o}$ is $\mathrm{F}$ which are being made with each assertion are being made for reasons that are permissive with respect to two criteria for whether o is $\mathrm{F}$, such that on one, o counts as $\mathrm{F}$ but on the other it does not. If we have that, then we get faultless disagreement. If not, then we don't. It seems then that faultless disagreement arises when the broader non-communicative goals of the relevant pair of asserters fail to place sufficient instrumental constraints on the criteria employed for deciding whether some item falls into a given category: the rich, the funny. This absence of constraint is not something that can happen only for a special class of "subjective" predicates.

\section{Some consequences of rejecting (SP)}

The position I'm putting forward here about when faultless disagreement is possible has implications for both contextualist and relativist analyses of the meanings of subjective predicates. Assume that the content of a sentence is a function from indexes to truth-values. The relativist thinks that whereas predicates of personal taste have a built-in, context-invariant metasemantics which lets a context of assessment (rather than of assertion) set a parameter in the index, other predicates have a built-in, context-invariant metasemantics which lets only the context of assertion (rather than of assessment) set the parameters in the index (e.g. MacFarlane 2014). This predicate-based analysis is adopted because the relativist thinks that the 
possibility of faultless disagreement is to be explained by the kind of predicate employed. But the examples presented above suggest that this is a mistake. If a relativist analysis is the best way to account for the possibility of faultless disagreement, then the metasemantics itself should be context-sensitive in the following respect: there is variation across contexts of assertion in whether a sentence containing a predicate has its judge index set by the context of assertion (and so doesn't permit faultless disagreement) or instead by a context of assessment (and so does permit faultless disagreement). It shouldn't be a context-invariant feature of the predicate that it is one or the other.

Contextualists understand the faultlessness of faultless disagreement as arising from a divergence of contents for the predicate employed in the two relevant assertions (a divergence that makes possible the consistency of the sentences containing these predicates). Different contextualists adopt different accounts of the impression of disagreement. For instance, Zakkou (2019) proposes that the impression of disagreement arises because asserters are pragmatically conveying propositions to the effect that their own criterion for determining what is $\mathrm{F}$ is the best: propositions which are inconsistent. Others understand the impression of disagreement as arising out of a practical conflict of some sort. For instance, Barker (2013) and Sundell (2011) think that the impression of disagreement reflects a disagreement about how an expression should be employed, whereas Marques' (2014, 2016) and Marques and García-Carpintero's (2014) think the impression of disagreement reflects asserters' possession of desires about what asserters desire, where these higher order (de nobis) desires cannot be jointly satisfied. The position defended in this paper has implications for at least some of these views (just as it does for the relativists). I have space to discuss just one of these views.

Although I want to be a little cautious in ascribing this view, it seems at least in places that Barker (2013, 247-49) and Sundell (2016, 808-17) (as well as Kennedy 2013, 274 and Khoo and Knobe 2018, 21-27) are constructivists about the content of context-sensitive expressions: they think that such expressions have the contents they do because there is an agreement between their users that these expressions have these contents. So when this agreement falls away (as in a metalinguistic dispute about 
how the expressions ought to be used), there is no fact of the matter about the content of the relevant expression. Like the position defended in this paper, constructivism implies that faultless disagreement is in principle possible almost anywhere (or at least, wherever context-sensitive language is employed). But in contrast with the position here defended, constructivism implies that a metalinguistic disagreement creates faultlessness. This is because, given constructivism, such disagreement just is the absence of what makes fault possible (i.e., metalinguistic agreement and the resultant linguistic fact). The observations made in this paper suggest that this isn't quite right. When the reasons for which the assessments are being made are not permissive, a metalinguistic disagreement can only be an exploration of linguistic facts that are already there (rather than yet to be constructed through the achievement of agreement). If, for instance, the reason for which assessments are being made require that persons with (only) one million dollars of spare cash be classified as below the threshold for being rich (as in example 3), then (if we understand faultlessness along contextualist lines) that's part of the content of "is rich" in the context. If a disagreement breaks out about this, the disputants will be exploring a pre-existing normative landscape - one put in place by the reasons for which they are making their assessments of whether someone is rich (metalinguistic disagreement is an exploration of the normative implications of pre-existing practical commitments). Consequently, the disagreement will be faultless only if the reasons for which assessments are being made are permissive (if not, we have a situation like example 2 or example 3 , wherein either there's no disagreement or someone is making a mistake). Sundell seems to suggest something incompatible with this when he explains why persons would ever be motivated to engage in a metalinguistic disagreement: to convince his readers of this, he points to just those circumstances in which the reasons why assessments are made are not permissive. If the position defended in this paper is correct, such contexts won't make disagreements faultless (because such contexts resemble either example 2 or example 3 ). The contexts capable of giving rise to faultless (on the contextualist analysis, metalinguistic) disagreements are those in which disputants are not pursuing the kind of demanding non-communicative tasks Sundell envisages. They're instead 
engaged in tasks that don't undermine the impression of disagreement but which also fail to give language the rigour needed to make anyone in the disagreement mistaken. ${ }^{2}$

Of course, this raises a question. Sundell explains why two people would be motivated to express and pursue a metalinguistic disagreement because of the consequences that depend upon the content with which the relevant predicate is employed. But if faultless disagreement arises in a context where nothing much hangs on with which content a predicate is used, then what motivates this behaviour? Well, there are motivations that don't depend upon there being any weighty contextual consequences to the choice of content to assign a context-sensitive word. Argument can be used simply as a form of sociability: done for itself, for kicks (Schiffrin, 1984). It can be used to do identity display, and show off who one is (Davies, forthcoming). It can be used to make fun of someone ("That's not a knife..."). It might even be that the disputants do not know that they're in such a context, and so use argument to find that out for themselves whether one content is more suited to their purposes than the other, and for it to be difficult to discern that one is no worse than the other.

\section{Objections and replies}

I turn now to four objections that might be raised against the hypothesis that faultless disagreement is made possible when assessments are being made for permissive reasons (rather than because a special kind of predicate is being employed).

2 The difference between constructivism and the position defended in this paper parallels a broader debate between those who favour a metasemantics of contextsensitive expressions that places greatest emphasis upon the agreement of the users of those expressions (e.g. King 2013 and Michaelson 2014), and those who favour a metasemantics that places greatest emphasis upon the non-linguistic actions in which the use of language is embedded (e.g. Davis 2018 and Dobler 2019), as the source of what makes a given expression have the content it does in a given context. 


\subsection{But that's just "rich"}

One concern is that examples 1-5 all involve the same predicate "is rich" and one might worry that what goes for this predicate doesn't go for others. I don't have the space to reproduce the same kind of examples that I have given above for other predicates. Doing this would also take space away from other things I should be doing here. But other examples are easy enough to construct on the template provided by examples 1-5. We find a predicate "is F/are F / Fs / F-ed" and we find some object we might apply this predicate to (where the object could be a particular or a kind), where the predicate and the object are such that, the predicate denotes a property such that we can think of two criteria which establish whether an object has that property such that on one criterion, the object doesn't have the property but on the other criterion it does. We then build the different sorts of context found in table 2. For example, take Office Author from the opening of this paper. What is required to be the author of something? Here are two ways to think of that. On the first, Gervais is the author of The Office only if he has authority over its interpretation: Gervais' intentions behind the scripts determine the content of the script. On the second, Barthesian way to think of authorship, Gervais is just a "scriptor", a person who creates the scripts, but who's intentions do not have any authoritative role in deciding what the content of the script is. We could imagine that there is a pair of people, one asserts "Gervais is the author The Office" and one asserts that sentence's negation, and in asserting what she does, each has a different view about what is required to be the author of something. And we can imagine these assessments of whether Gervais is the author being made by each asserter through her respective assertion being done for various different reasons. Sure enough, if, for instance, they are each speaking for idle reasons, then we'll have a situation much like we see in example 1; one in which there's an impression of faultless disagreement. If on the other hand, each makes her assessment for a non-permissive reason, then we'll either lose the impression of disagreement (as in example 2) or we'll lose the impression of faultlessness (as in example 3), depending upon further details about their respective non-permissive reasons for making their respective assessments. 


\subsection{Elaboration objections}

Several have presented the following objection to the possibility of what I'm describing (Hawthorne 2004, 104; Marques \& García Carpintero 2014, 712-14; Schaffer 2011, 213; Stanley 2005, 55-56). The objection is that when we allow further elaboration on what each asserter meant by her assertion, then the sense that they disagree vanishes. For instance, consider the following two assertions:

\section{Example 8}

A (assuming Yasser is 1.96 metres tall, discussing the height of basketball players): Yasser is short.

$\mathrm{C}$ (responding to A, and aware that the height of basketball players is discussed, but who has a different very precise perspective on how to draw the line of height for players, which has led him to draw the line for shortness at 1.956 metres assuming the same about Yasser as A): Yasser is not short.

At first glance, this looks like a case of disagreement. A thinks that Yasser is short because A thinks that to be not short you need to be taller than 1.96 metres. $\mathrm{C}$ thinks that Yasser is not short because $\mathrm{C}$ thinks that if you are taller than 1.956 then you are not short. But, what if the following elaboration is offered by A?:

A: That does not contradict what I said; I was just saying that Yasser is short for a basketball player on rough estimates for the purposes of coffee talk. I was not contemplating your own estimate; thus I was not wrong. (Marques \& García Carpintero 2014, 712-14)

Sure enough, if this elaboration is offered (and true), then, I concur, the impression of disagreement between the two assertors vanishes. But notice that in this elaboration a distinction of the reasons why the two assertions are being made is drawn: A was making an assessment for 'purposes of coffee talk' whereas $\mathrm{C}$ was making an assessment presumably for other purposes - or else there would be little point in A drawing attention to her own. In other words, the elaboration offered as evidence against Richard makes the whole scenario better resemble example 2 than Richard's original example 1 (For further discussion see Davies 2017). 
In response to this, one might object to the purported importance of the reasons for which each asserter is making an assessment of Yasser's shortness. One might think that for an elaboration to dislodge the impression of disagreement, it suffices to point out that each asserter draws the line for being short differently. That in and of itself suffices to show that they don't disagree about whether Yasser is short: appeals to relevant differences in the reasons for which each asserter is making her assessment are unnecessary.

But surely this is an exaggeration. Two people can perfectly well be in a state of disagreement about whether o is $\mathrm{F}$ because (not despite the fact that) they disagree about what is required or sufficient for something to be F. The Russian government thinks that Estonia freely voted itself into the Soviet Union. The Estonian government disagrees: Estonia was occupied by the Soviet Union, it did not freely vote itself into the Soviet Union. The Russian and Estonian governments very likely have different understandings of what is required for Estonia to have freely voted itself into the Soviet Union. That doesn't mean the governments don't disagree about whether Estonia freely voted itself into the Soviet Union. Differences of this sort just don't have the capacity, in and of themselves, to undermine the presence of a state of disagreement. Likewise, the mere fact, in and of itself, that A and $\mathrm{C}$ think that shortness is marked off at different points on a scale of height doesn't show that they don't disagree about whether Yasser is short. If the impression of disagreement is to vanish, it is important to distinguish different reasons why the assessments of Yasser's height were being, with it being clear that the reasons for making each assessment favour the respective assertions. If that isn't clear, then it might become unclear whether we have in hand an example which most closely resembles any one of our earlier examples 1-5. But that unclarity wouldn't show that there are no examples like 1.

Anyone who accepts that faultless disagreements are possible and that the best account of them makes the faultlessness veritic must accept that a mere difference in the way persons draw the extensional boundary for what is $\mathrm{F}$ doesn't suffice to disqualify them from being in a state of disagreement with one another. It would be incoherent to then insist that such differences do suffice to thwart disagreement. 


\subsection{Comparative predicates}

It has been claimed that faultless disagreement may be possible with an objective predicate like "tall" but not with the same adjective's comparative form and that, in this respect, the adjective itself "tall" seems to differ from, for example, the adjective "fun" (Kennedy 2013, 269; Solt 2018, 60; and Umbach forthcoming, 5). For example, consider the following pair of pairs of assertions provided by Solt $(2018,60)$ :

\section{Example 9}

Speaker A: The chili is tastier than the soup!

Speaker B: No, the soup is tastier!

\section{Example 10}

Speaker A: Anna is taller than Zoe.

Speaker B: No, Zoe is the taller of the two!

Solt classifies example 9 as a faultless disagreement. She classifies example 11 as factual only. And just looking at these as they stand, ignoring what more may be going on in contexts of each pair, I agree that the pair of pairs of assertions give rise to the impression Solt describes. However, I nonetheless think it possible for an impression of faultless disagreement to arise when the relevant pair of assertions includes use of the comparative form of "tall". What's difficult about thinking of ways in which this could happen is that whether one item is taller than another is not something that could be open to dispute by two reasonable people who each have made no mistake about how tall the two items are. ${ }^{3}$ But if we can find ways in which different scales of height would result in different orderings of the two items then, it seems, there'll be room for two people to disagree about which is taller than the other without either having made a mistake (provided that the reasons for which each makes her assertion are permissive with respect to the categorization of these two items in terms of their relative heights). Consider the following example:

3 "Taller than" seems not to be multidimensional (Kennedy, 2013). My point here is that it's not impossible for "taller than" to be multidimensional. 


\section{Example 11}

During the course of a day, in some sense, your height changes. This happens because the spinal discs between your vertebrae are largely made of water. When you place weight on the disks in your back (as when you are standing or sitting upright), they compress (over the course of several hours). But when you're lying down, they expand. Ana, Bea, Cat and Dee are four competitive girls. They compete over everything: who can fit the most gob-stoppers in her mouth, who can jump the furthest etc. Suppose that Ana recently broke a leg and for this reason spends most of each day lying down. When they stand against a wall, Ana's height is a centimetre or so higher than Cat's. Suppose that if Ana and Cat had been lying down all day, then Cat would be taller than Ana. Being competitive girls, each girl wants to be taller than the other. For that reason, Cat adopts the view that the proper way to compare two persons' heights is to ensure that they have both been lying down for the same amount of time prior to measurement. For the same reason, Ana adopts the view that the proper way to compare two persons' heights is to stand them against a wall and measure their heightsregardless of whether one of them has been lying down recently. Finally, suppose that Bea is a friend of Ana's who agrees with Ana about the proper way to measure relative height and Dee is a friend of Cat's who agrees with Cat about the proper way to measure relative heights. Now, suppose that in one context, Ana and Cat are talking about whether Ana or Cat is taller, and in another context, Bea and Dee are talking about whether Ana or Cat is taller. In each context, there's nothing but banter going on: these are permissive contexts. Nothing in either context settles how relative height is to be understood in that context. In the first context, Ana says, "I am taller than you," and in the second context, Dee says, "Ana is not taller than Cat." (Davies 2017, 871)

Ana and Dee are in a state of disagreement. But neither need be mistaken in her assessment. The difference in impression we get between examples 9 and 10 is not a context-invariant effect. 


\subsection{Experimentally demonstrated differences}

Experimental findings indicate that if a person is presented with a pair of assertions, whether she will think that faultless disagreement is possible for that pair of assertions will be affected by the predicate employed in the pair; i.e. by whether it is paradigmatically subjective or not (see Cova \& Pain 2012 and Solt 2018, 65). If the reasons for which assessments are being made by the asserters are not provided, then, it might seem, we should predict that there would be no difference in reaction to sentences containing different kinds of predicate. Since there is, this speaks against the view that the reasons for which assessments are made play a crucial role in determining where impressions of faultless disagreement arise.

But I don't think we're forced to accept this conclusion. When we hear certain combinations of words, we are more likely to associate the combination with one kind of context than another. Hear the words "would you like fries with that?" and we think of a cashier at a fast-food restaurant inviting us to expand our initial order. Hear the words "tuck your shirt in!" and we imagine a teacher ordering around a schoolchild. But these sentences don't need to be used in only those contexts that come first and most strongly to mind when we hear them out of the blue. Words make certain contexts salient. But this doesn't mean that the features the words have when thought of as used in a most salient context are context-insensitive properties of the words themselves.

Given this, it is even to be expected that when presented out of the blue with a pair of assertions of sentences that include, for instance, predicates of personal taste, we will be inclined to imagine their use in a salient kind of context, whereas when presented with a pair of assertions made using a kind of predicate typically classified as "objective", we are inclined to imagine their use in a (different) salient kind of context. If the most salient contexts of use differ in whether the reasons for the assessments made with the respective assertions are permissive in the right way, then we'd expect what's witnessed by Cova and Pain, and by Solt. But this wouldn't count against the position being defended in this paper.

On the contrary, the position defended in this paper implies that there is a potential confound in these studies' designs, insofar as these studies are used to derive conclusions about predicates per se. If one is interested in 
where and why faultless disagreement seems possible, and if context makes a difference to this in the way seen in our examples 1-7, then that factor should be controlled for. To date, they haven't been. It's just been supposed that if no context is provided, then context plays no role in patterns of impressions of faultless disagreement.

\section{Acknowledgements}

I'd like to thank the participants of the University of Tartu Theoretical Philosophy WiP seminar, the referees for Organon $\mathrm{F}$ and the editor of this issue for pushing me to improve this paper far beyond the state of the original submission. The research that led to this paper was supported by the European Union's Regional Development Fund through the Centre of Excellence in Estonian Studies.

\section{References}

Barker, Chris. 2013. "Negotiating Taste." Inquiry 56 (2-3): 240-57. doi.org/10.1080/0020174X.2013.784482

Cova, Florian, and Nicolas Pain. 2012. "Can Folk Aesthetics Ground Aesthetic Realism?" The Monist 95 (2): 241-63. Retrieved from https://www.jstor.org/stable/41419025

Davies, Alex. 2017. "Elaboration and Intuitions of Disagreement." Philosophical Studies 174 (4): 861-75. DOI: 10.1007/s11098-016-0710-7

Davies, Alex. 2018. "Communicating by Doing Something Else." In The Philosophy of Charles Travis, edited by Tamara Dobler, and John Collins, 135-54. Oxford: Oxford University Press.

Davies, Alex. forthcoming. "Identity Display: Another Motivation for Metalinguistic Disagreement." Inquiry. https://doi.org/10.1080/0020174X.2020.1712229

Dobler, Tamara. 2019. "Occasion-Sensitive Semantics for Objective Predicates." Linguistics and Philosophy 42 (5): 451-74. https://doi.org/10.1007/s10988-0189255-x

Glanzberg, Michael. 2007. "Context, Content and Relativism." Philosophical Studies 136 (1): 1-29. doi.org/10.1007/s11098 00791455.

Hawthorne, John. 2004. Knowledge and Lotteries. Oxford: Clarendon Press.

Huvenes, Torfinn Thomesen. 2014. "Disagreement without Error." Erkenntnis 79 (1): 143-54. doi.org/10.1007/s10670-013-9449-0 
Kennedy, Christopher. 2013. "Two Sources of Subjectivity: Qualitative Assessment and Dimensional Uncertainty." Inquiry 56 (2-3): 258-77.

https://doi.org/10.1080/0020174X.2013.784483

Khoo, Justin, and Joshua Knobe. 2018. "Moral Disagreement and Moral Semantics." Nous 52 (1): 109-43. https://doi.org/10.1111/nous.12151

King, Jeffrey C. 2013. "Suplementives, the Coordination Account and Conflicting Intentions." Philosophical Perspectives (27): 288-311. https://doi.org/10.1111/phpe.12028

Kölbel, Max. 2003. "Faultless Disagreement." Proceedings of the Aristotelian Society: Supplementary Volume 104: 53-73. doi.org/10.1111/j.00667373.2004.00081.x

Kolodny, Niko. 2018. "Instrumental Reasons." In The Oxford Handbook of Reasons and Normativity, edited by Daniel Star, 731-64. Oxford: Oxford University Press.

Lasersohn, Peter. 2005. "Context Dependence, Disagreement, and Predicates of Personal Taste." Linguistics and Philosophy 28: 643-86. doi.org/10.1007/s10988-005-0596-x

MacFarlane, John. 2014. Assessment Sensitivity: Relative Truth and Its Applications. Oxford: Oxford University Press.

Marques, Teresa. 2014. "Disagreeing in Context." Frontiers in Psychology (6): 112. https://doi.org/10.3389/fpsyg.2015.00257

Marques, Teresa. 2016. "We Can't Have No Satisfaction." Filosofia Unisinos 17 (3): 308-14. https://doi.org/10.4013/fsu.2016.173.07

Marques, Teresa, and Manuel García-Carpintero. 2014. "Disagreement about Taste: Commonality Presuppositions and Coordination." Australasian Journal of Philosophy 92 (4): 701-23. doi.org/10.1080/00048402.2014.922592

Michaelson, Eliot. 2014. "Shifty Characters." Philosophical Studies 167 (3): 519-40. https://doi.org/10.1007/s11098-013-0109-7

Palmira, Michele. 2015. "The Semantic Significance of Faultless Disagreement." Pacific Philosophical Quarterly 96 (3): 349-71. doi.org/10.1111/papq.12038

Richard, Mark. 2004. "Contextualism and Relativism." Philosophical Studies 119 (1-2): 215-42. doi.org/10.1023/B:PHIL.0000029358.77417.df

Schaffer, Jonathan. 2011. "Perspective in Taste Claims and Epistemic Modals." In Epistemic Modality, edited by Andy Egan, and Brian Weatherson, 179-226. Oxford: Oxford University Press.

Schiffrin, Deborah. 1984. "Jewish Argument as Sociability." Language in Society 13 (3): 311-35. https://doi.org/10.1017/S0047404500010526

Solt, Stephanie. 2018. "Multidimensionality, Subjectivity and Scales: Experimental Evidence." In The Semantics of Gradability, Vagueness and Scale Structure. 
Experimental Perspectives, edited by Elena Castroviejo, Louise McNally, and Galit Weidman Sassoon, 59-91. Cham, Switzerland: Springer.

Stanley, Jason. 2005. Knowledge and Practical Interests. Oxford: Oxford University Press.

Stojanovic, Isidora. 2007. "Talking about Taste: Disagreement, Implicit Arguments, and Relative Truth." Linguistics and Philosophy 30 (6): 691-706. doi.org/10.1007/s10988-008-9030-5

Stojanovic, Isidora. 2019. "Disagreements about Taste vs. Disagreements about Moral Issues." American Philosophical Quarterly 56 (1): 29-41.

https://www.jstor.org/stable/45128641

Sundell, Timothy. 2011. "Disagreements about Taste." Philosophical Studies 155: 267-88. https://doi.org/10.1007/s11098-010-9572-6

Sundell, Tim. 2016. "The Tasty, the Bold and the Beautiful." Inquiry 59 (6): 793818. https://doi.org/10.1080/0020174X.2016.1208918

Umbach, Carla. forthcoming. "Evaluative Predicates beyond 'fun' and 'tasty'". In The Wiley Blackwell Companion to Semantics, edited by Daniel Gutzmann, Lisa Matthewson, Cécile Meier, Hotze Rullmann, and \& Thomas Ede Zimmerman. Hoboken: Wiley-Blackwell.

Wright, Crispin. 2001. "On Being in a Quandary: Relativism, Vagueness, Logical Revisionism." Mind 110: 45-98. doi.org/10.1093/mind/110.437.45

Zakkou, Julia. 2019. Faultless Disagreement: A Defense of Contextualism in the Realm of Personal Taste. Frankfurt: Verlag Vittorio Klostermann. 